\title{
Liberating the NHS; commissioning, outsourcing and a new politics debate
}

\author{
Paul Regan, Elaine Ball \\ Paul Regan, Lecturer in Adult Nursing, School of Nursing and Caring Sciences, University of Central Lancashire, Elaine Ball, \\ Lecturer in Adult Nursing, School of Nursing and Midwifery, University of Salford \\ Email:PJRegan@uclan.ac.uk
}

$\mathrm{T}$ he UK Government set out its agenda for the future of British democracy with a new politics emerging as an underlying principle in their Coalition programme (Cabinet Office, 2010). Now reflected in the White paper Equity and Excellence: Liberating the NHS (DH, 2010a) it aims to strengthen the collective voice of patients and the public, increase practitioner autonomy, save money, reduce management costs, bureaucracy and inefficiencies by promoting general practitioners' (GP) consortia commissioning to provide services directly. The White paper identifies sweeping reforms that aim to dissolve strategic health authorities and primary care trusts (Wise, 2010), despite excellent developments over the last few years in developing world class commissioning and tackling health inequalities (DH, 2009). In its place GPs are to be encouraged to join other GP commissioning consortia and with an expansion of payment by results (PBR), an expectation they will eventually command up to $80 \%$ of the total NHS budget (Wise, 2010). Of course the caveat is that any commitments made in the White paper are subject to parliamentary legislation and there is time for discussion with patients' and professional association's notwithstanding critical debate from the medical profession central to proposed reforms that open up the public purse to alternative providers (DH, 2010a). Therefore as part of that debate we will return to discuss the new politics underlying the Coalition's consensus government.

In this article, the term 'incentivise' will be used to mean to provide incentives to motivate staff (AQ: Ok?)

\section{New politics}

What does a new politics mean for the UK and more specifically for the NHS in light of the proposed expansion of commissioning reforms? The term new politics can be defined as a:

'better kind of politics...orientated less to the pursuit of individual self interest and more to the purpose of the common good...' (Sandel, 2009a, p1)

driving a need for more critical engagement of the general public (and our health-care workforce) and tackling moral political issues) through citizens encouragement to have a bigger say in the NHS (DH, 2010a). This appears to be critical to the new reforms but with untested plans to create the world's biggest social enterprise by promoting competition between services there are risks that reforms go too far by incentivizing markets previously motivated by altruism in the NHS for the health and wellbeing of society (Sandel, 2009a,). The reforms, driven by the international recession effects on the UK gross domestic product (GDP) means that tough decisions are being taken to secure future services coupled with a moral obligation to release as much money as possible into supporting front-line care $(\mathrm{DH}$, 2010a). However, as will be discussed, commissioning and the role of alternative providers appears to cost more in financial terms (Unite, 2009; House of Commons Health Committee (HC), 2010) with moral implications of public ownership (Sandel, 2009a). Before going onto the latter issue, the authors will first consider the issue of incentivizing being cost in-effective (Hopper, 2009; HC 2010).

\section{So far, so quilckly}

The publication of the McKinsey report (DH, 2010b) demonstrated the Coalition government's new approach to informing public debate and a need to make necessary changes. Completed in March 2009 (for the then government) to review the second year of world class commissioning through Transforming Community Services (TCS, $\mathrm{DH}, 2009)$ the report emphasised the need to increase productivity and concluding savings could be made through more health prevention measures (DH, 2010b). However, contrasting with concerns for more coherent, inclusive and well thought through NHS reforms (Ball and Regan, 2010), McKinsey suggest a need to eliminate

\section{ABSTRACT}

In the short months following the result of the UK 2010 General election, a new Government White Paper has been released entitled: Equity and Excellence: Liberating the NHS (Department of Health (DH), 2010a). It strives to distance itself from previous health-care proposals $(\mathrm{DH}, 2009)$, yet if the initiatives of this latest paper are combined against previous initiatives, also using high impact declarative terms, such as competition and choice, it is clear that little has changed and more important principles than saving money are at risk.

\section{KEY WORDS}

Transforming community services • Outsourcing • New politics • Markets $•$ Commissioning 
'incentivising through

payment by results now underpins the English NHS funding system' and remove barriers to change such as mandatory workforce ratios (that are in place to ensure patient safety and quality care), reducing the variability of sickness levels, frequency of community nurses home visits (DH, 2010b) and increasing productivity by doing more with less staff. In contrast, Kaiser Permanente in the United States reportedly achieved shorter lengths of in-patient costs with more senior doctors employed per capita (Paton, 2010) suggesting 'the do more for less argument' (Ball and Regan, 2010) contrasts with the quality and quantity of staff being seen as important factors to improving cost and clinical effectiveness (Paton, 2010).

\section{"Any provider" - outsourcing by any other name}

In May of this year the Health Secretary Andrew Lansley talked about the Coalition's aim to give patients' the choice to choose:

$$
\begin{aligned}
& \text { '...any healthcare provider that meets NHS stand- } \\
& \text { ards...(including) independent, voluntary and } \\
& \text { community sector providers...' (Coalition pro- } \\
& \text { gramme, Cabinet Office, 2010) }
\end{aligned}
$$

This is reinforced in July's publication of the White paper (DH, 2010a) intending to extend choice to all service users, including choice for alternative providers to compete for tendered NHS services (DH, 2010a). The mechanism of 'any provider' promotes competition and choice linked to commissioning, TCS and outsourcing as seen in previous initiatives (DH, 2009; Unite, 2009). Outsourcing within the NHS became prevalent in the late 20th century and is viewed by critics as a way of managing a problem a company cannot solve or have become disinterested in (Hopper, 2009). By transferring responsibility for the task onto someone else brought with it issues of quality, control, reduced innovation and the rise of technocrats using outcomes that quantify and measure efficiency within narrow parameters of cost benefit analysis. Therefore outsourcing appears to be closely aligned with definitions of health-care privatization such as; reducing the role of government, deregulation of state monopolies, outsourcing of state responsibilities and ending services offered by the state; all indicative of privatization (Starr, 1988). Let us not forget private companies also sub-contract to other providers adding to a fragmentation risk of tendered services (Unite, 2009).

Growing criticism before the new White paper ( $\mathrm{DH}$, 2010a) suggested reforms that maintain the purchaser/ provider split had become increasingly untenable (Unite, 2009; Paton, 2010). The outsourcing issues through commissioning (GP or TCS) are said to be contentious on differing levels. The most pressing national issue is to save $£ 167 b$ national debt (8\% GDP) and deal with the expected NHS funding gap of $10-£ 15$ b in $2013 / 14$ by increasing productivity and meeting new austerity measures for the
UK population (DH, 2010a; 2010b). Much work has gone into developing and promoting TCS commissioning but it has been hampered by resistance to fears of privatization, frequent and confusing re-organization (Paton, 2010) and costs rising to $14 \%$ of the overall NHS budget challenging the notion to save money by expanding the commissioning agenda (HC, 2010). Unite (2009) also remain unconvinced of the cost benefits of commissioning (TCS and outsourcing), citing private US health-care spending over $16 \%$ of its GDP on health while over 45 million Americans, until recently, lacked any health insurance at all. In contrast, the UK spends half that through the NHS and covers all whether contributing through taxes or not (Unite, 2009).

\section{A new morality}

The case for a new politics appears to be in contrast to the commissioning expansion in light of a moral debate by the economist Michael Sandel in his 2009 BBC Reith lectures calling for a critical discussion on markets, morals (2009a; $2009 b$ ) and a new politics for the common good (2009c). A new politics requiring more authentic public discourse with politics and debating the moral meaning and limits of markets into areas of US and UK public life, such as education and healthcare (2009a). Let us expand on these issues further.

\section{Incentivizing (payment by results)}

The White paper suggests:

'providers will be paid according to their performance. Payment should reflect outcomes, not just activity and provide an incentive for better quality' (DH, 2010a, p4).

But what can be made of such a pronouncement, not in the reputed savings to be made but in light of a new politics? Running the NHS along market lines means that all aspects of services will be required to be bought and sold, adding to current costs leading us to ask the question; why incentivize services when the NHS already benefits from the public's altruistic motivations to give (as taxpayers) and serve (as NHS employees) our society's healthcare needs (Unite, 2009)? In other words, the public are already incentivized out of their motivation for the common good. However, incentivizing through payment by results (PBR) since 2006 now underpins the English NHS funding system meaning that providers are paid by NHS Trusts (as purchasers or commissioners) for contracted services without a guaranteed future funding and as a result creating powerful incentives to choose patients' with less complex cases so that more can be treated and more profit made (Unite, 2009). Hence, NHS bodies are not only in competition with each other to attract patients' but with 'Choose and Book' in secondary care came the arrival of large multi-national healthcare providers (e.g. United Health, Netcare, Care UK). However, the House of Commons health select committee challenged the rationale for introducing the private sector into the NHS to 
improve waiting times found the achievements were largely as a result of the NHS, not the private sector, so the rationale now has changed to competition and choice (Unite, 2009). In the US, when comparing the UK which had (so far) banned financial incentives for improving the quality and quantity of blood donations, incentivizing by payment led to higher rates of product contamination and people feeling less obligated to give out of altruism (Sandel, 2009a). As seen in the US such a pervasive attitude impacts negatively on health and social inequalities where critics aim to protect the healthcare conglomerates market positions (2009c). In order to address this potential UK shift, Sandel asks how we value goods and social practises that have drifted away from a market economy to a market society (2009c). Hence, a hope for civic renewal requires us to challenge the market's objectification of people that are seen as bargaining chips through the language of markets norms (2009c) and a return to preincentivized, more cost- and morally-effective times (Unite, 2009). The authors therefore suggest a need to think through the moral limits and the de-valuing effect of for- profit markets involvement in UK public policy (Sandel, 2009a).

\section{Sandel's market mimicking governance}

The market economy was perceived to be the answer to achieving national prosperity, growth and the public good (Sandel, 2009c) but after three decades of market forces and de-regulation, there is a timely need to re-evaluate the reach of markets into areas of public policy (2009a). It is important to remember that faith in markets is the reason for the financial crisis in the first place, driven by profit margins and to its critics the greed critique $(2009 \mathrm{c}$,). A faith that led to markets becoming involved in all areas of public life in what Sandel calls 'market mimicking governance' (2009c); attractive as a style of governance because it offers the perception of political engagement and choice but in effect tends to distract away from moral debate on the rights and wrongs of case and effect (p8). This is what the Coalition government are doing in a:

\section{'...forthcoming health bill (that) will give the NHS greater freedoms and help prevent political micro-management...' (DH, 2010a).}

In the end society is not being asked to place a value on the cost a service deserves, because markets will do that for themselves through competition and methods such as cost benefit analysis that quantify everything including life itself (Sandel, 2009a). Therefore, the idea for a reinvented morality of politics envisions viewing society less as (market) consumers and more as re-empowered citizens (2009c); in part because 'market mimicking governance assumes people's preferences are given and fixed' and only by engaging in critical debate can preferences be made clearer. Sandel therefore calls for continued national solidarity and civic virtue with critical debate on public ownership.

\section{Conclusion}

With the Coalition's new rhetoric, it does not seem that lessons from industrial and business critics about commissioning (outsourcing) have been learnt (Hopper, 2009). In the commissioning context (DH, 2009; 2010a) a new politics appears to involve processes that are a form of distanced responsibility and allowing market forces to dictate a moral political vacuum (Sandel, 2009c). GPs and alternate providers are businesses and national debt appears to drive forward radical reforms but recovery might not be found in the limitations of markets and financial procurement reforms alone that have already cost so much and failed to deliver on promises (HC, 2010). A new direction reflecting market scepticism (of competition) should include a regained moral imperative and direction in the UK - one that reverses the corrosive effect of market forces on public policy that does not outsource to 'any willing provider' but instead supports the principles of new politics and liberating the NHS from being shaped by market forces (DH, 2010a). BJCN

Ball E, Regan P (2010) Change and the NHS workforce: ambivalence, anxiety and anger. Nurse Education in Practice 10: 113-4

Cabinet Office (2010) The Coalition; our programme for government. HM Government, London

Department of Health (2009) Transforming Community Services: Enabling new patterns of provision. HMSO, London

Department of Health (2010a) Equity and excellence: Liberating the NHS. HMSO. London

Department of Health (2010b) Achieving world class productivity in the NHS 2009/10 - 2013/14: Detailing the size of the opportunity. McKinsey and Co. http://tinyurl.com/39esec8 (Accessed 2 September 2010)

Hopper K, Hopper W (2009) The puritan gift; reclaiming the American dream amidst global financial chaos. I.B. Tauris, London-New York

House of Commons Health Committee (2010) Commissioning; 4th report of session 2009-10, volume 1, 30th March, HC268-1

Paton C (2010) Commissioning in the English NHS; a failing system that needs to be abandoned. British Medical Journal 340: c1979

Sandel M (2009a) Markets and morals. 9th June. The BBC Reith lectures.http:// www.bbc.co.uk/programmes/b00kt7sh (Accessed 2 September 2010)

Sandel M (2009b) Morality in politics. 16th June.The BBC Reith lectures. http:// www.bbc.co.uk/programmes/b0010y01 (Accessed 2 September 2010)

Sandel M (2009c) A new politics of the common good. 30th June. The BBC Reith lectures. http://www.bbc.co.uk/programmes/b00lb6bt (Retrieved paper $16 / 7 / 10)$

Starr P (1988) The meaning of privatisation. Yale Law and Policy Review 1988. 6. http://www.princeton.edu/ starr/meaning.html (Accessed 2 September 2010)

Unite (2009) The patchwork privatisation of our health service; a users' guide. Unite, London. http://tinyurl.com/2ur58a4 (Accessed 2 September 2010)

Wise J (2010) GPs are handed sweeping powers in major shake up of NHS. British Medical Journal (July 14th) 341: c3796

\section{KEY POINTS}

- Transforming Community Services (TCS) encouraged NHS services to compete with alternative providers through commissioning.

- The Coalition government's idea of a new politics aims to promote critical discussion, transparency and public engagement in the NHS.

- Equity and Excellence: Liberating the NHS (DH, 2010) identifies a new direction for the NHS by increasing freedom, social enterprise, GP consortia commissioning up to $80 \%$ of the NHS national budget and competition opened up further to alternative providers.

- These reforms are more unprecedented than TCS commissioning and controversially lack precedent, detail and costing implications.

- The marketization of health care, as seen in the US and now in the UK's NHS risks a corrosive effect on democracy as governments distance themselves from moral questions as market forces shape the new NHS (Sandel, 2009a). 